PROF. MIN ZHANG (Orcid ID : 0000-0001-8107-5212)

3

4

5

Article type : Original Article

6

7

8 Effects of reheating methods on the product quality of Hongsu

9 chicken dish

10

${ }^{1}$ State Key Laboratory of Food Science and Technology, Jiangnan University, 214122 Wuxi,

${ }^{2}$ Jiangsu Province Key Laboratory of Advanced Food Manufacturing Equipment and Technology, Jiangsu, China

${ }^{3}$ Yangzhou Yechun Food Production \& Distribution Co., Yangzhou 225200, Jiangsu, China

${ }^{4}$ Faculty of Veterinary and Agricultural Sciences, The University of Melbourne, Parkville, Victoria 3010, Australia

*Corresponding author: Dr. Min Zhang, Professor of School of Food Science and Technology,

22 Jiangnan University, 214122 Wuxi, P. R. China.

23 Tel.: 0086-510-85877225; Fax: 0086-510-85877225;

24 E-mail: $\underline{\text { min@jiangnan.edu.cn }}$

\title{
25 Abstract
}

26 Hongsu chicken dish is a very popular commercially cooked, ready for home and office consuming meat product in Yangzhou city, China. Effects of different reheating

This is the author manuscript accepted for publication and has undergone full peer review but has not been through the copyediting, typesetting, pagination and proofreading process, which may lead to differences between this version and the Version of Record. Please cite this article as doi: 10.1111/ifpp.13823

This article is protected by copyright. All rights reserved 
methods including hot water boiling, steaming, microwave heating and oven roasting on the product quality attributes of Hongsu chicken dish were investigated. The results showed that the microwave reheated samples had the best sensory scores, least weight loss, the taste and texture were close to that of the freshly cooked meat, with attractive color and aroma. To reach the required center temperature of $72{ }^{\circ} \mathrm{C}$, the sample should be microwave heated at $480 \mathrm{~W}$ for $3.2 \mathrm{~min}$. This research suggested that the microwave treatment was a quick and convenient method for reheating Hongsu chicken dish.

KEYWORDS: Hongsu chicken dish, water boiling, steaming, microwave heating, oven roasting, product quality

Practical Applications : This study compared the effects of different reheating methods including water boiling, steaming, microwave and oven roasting treatment on the quality attributes (including water content, weight loss, color, texture, sensory evaluation, flavor and taste) of Hongsu chicken dish. The results showed that microwave heating at $480 \mathrm{~W}$ for 3.21 minutes was able to reach the sample center temperature of $72{ }^{\circ} \mathrm{C}$. Compared with other reheating methods, microwave reheated samples had the best sensory scores, least weight loss, and the taste was close to that of the freshly cooked meat. Therefore, this technique might have met consumers' requirements of convenient, quick and high quality reheated Hongsu chicken dish.

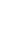

\section{1 | INTRODUCTION}

\section{(1)} city in China. It is a commercially prepared dish sold under refrigerated environment to extend shelf-life. The Hongsu chicken dish needs to be reheated before human consumption and the reheating process will further improve the product eating quality such as flavor, taste and appearance etc. The reheating process will also inhibit microbes to ensure food safety (Kerry, Kerry, \& Kerry, 2011). The traditional main heating methods for meat products are steaming, smoking, frying and roasting which mainly rely on heat conduction and convection to transfer energy (Sun, 2005). By using these methods, when the meat center temperature reaches the required safe temperature, the surface meat are generally overcooked (Wills, DeWitt, Sigfusson, \& 
Bellmer, 2006), which could result in nutritional and sensory quality losses. To meet consumers' requirements for high quality meat products, it is very important to explore alternative techniques to alleviate the disadvantages of traditional heating methods (Schellekens, 1996).

Microwave is an electromagnetic wave with a frequency ranging from $300 \mathrm{MHz}$ to $300 \mathrm{GHz}$. Microwave heating is very quick, because the electromagnetic waves can penetrate into the interior of the samples and convert into heat energy in a short time (Pu, Song, Song, \& Wang, 2017), which has the advantages of safe and easy operation, high energy efficiency, time saving and low maintenance (SalazarGonzalez, San Martin-Gonzalez, Lopez-Malo, \& Sosa-Morales, 2012; Zhang, Tang, Mujumdar, \& Wang, 2006). Comparing with the traditional heating methods, microwave heating can maintain the nutritional and sensory quality of food to a higher level (Vadivambal \& Jayas, 2010).

Although the application of microwave heating in fresh meat cooking has been extensively investigated (Ji, Xue, Zhang, Li, \& Xue, 2017; Kondjoyan et al., 2014; Liu \& Lanier, 2016; Lorenzo, Cittadini, Munekata, \& Dominguez, 2015), little is known about the comparison between microwave heating and traditional heating techniques on the quality of prepared meats. Therefore, the aim of this study was to evaluate the effects of reheating methods (including hot water boiling, steaming, microwave heating, roasting) on the product quality of Hongsu chicken dish. This research may have provided useful information in selection of appropriate reheating method before consumption of Hongsu chicken dish, and might be applicable for reheating of other prepared meat products.

\section{2 | MATERIALS AND METHODS}

\section{1 | Meat Materials}

Hongsu chicken dish was prepared by using boneless chicken drumsticks and skinless pork belly as main raw materials. The pork belly was firstly processed into ground meat, and mixed uniformity with ginger, scallion and other seasonings in a vacuum roller kneading machine. The boneless chicken drumsticks were steamed and then covered with a layer of the mixed ground meat. Then the dish was steamed, fried, and brined to obtain the final product. The prepared Hongsu chicken dish was provided by Yangzhou Yechun Food Production \& Distribution Co. Ltd. (Yangzhou city, Jiangsu province, China) under refrigerated conditions on the same day of 
cooking. The meat was aseptically cut into chunks $(13 \pm 0.5 \mathrm{~cm}$ in length, $4 \pm 0.5 \mathrm{~cm}$ in width and $1.5 \pm 0.5 \mathrm{~cm}$ in thickness) with weight about $50 \pm 5 \mathrm{~g}$ each, vacuum packed, and kept in a refrigerator at about $4{ }^{\circ} \mathrm{C}$ for 2 days before reheating.

98

99

100

101

102

103

104

105

106

107

108

109

110

111

112

113

114

115

116

117

\subsection{Heating Treatment}

The samples were divided into five groups (6 samples in one group) for reheating treatments, namely untreated (control), hot water boiling, steaming, microwave heating, and oven roasting. The initial temperature of the Hongsu chicken dish was $4 \pm 2{ }^{\circ} \mathrm{C}$ before the treatments.

\subsection{1 | Water boiling}

The sample was wrapped with a polyethylene bag and then slowly placed into the boiling water of a stainless-steel water bath. A fiber-optic temperature sensor (FISO Technologies Inc., Quebec, Canada) was inserted into the center of the sample and the sample was cooked until the temperature reached at $72{ }^{\circ} \mathrm{C}$.

\subsubsection{Steaming}

The sample was put on a plate, and then placed in a stainless-steel household steamer (Zhejiang Supor Co., Ltd., Hangzhou, China), and steamed at $100{ }^{\circ} \mathrm{C}$. The fiber-optic temperature sensor was inserted into the center of the sample and heated to $72{ }^{\circ} \mathrm{C}$.

\subsection{3 | Microwave}

The sample was placed in the center of a microwave oven (P70F20L-DG (S0), $2450 \mathrm{MHz}$ Galanz microwave oven, Guangdong, China). The output power of the microwave was $480 \mathrm{~W}$. The sample was also heated to the center temperature of $72{ }^{\circ} \mathrm{C}$.

\subsection{4 $\mid$ Oven roasting}

The sample was heated in a convection oven pre-heated at $180^{\circ} \mathrm{C}$. The center temperature of the sample was measured at regular intervals and heating was terminated when reached $72{ }^{\circ} \mathrm{C}$. 


\subsection{Measurements}

\subsection{1 | Moisture content analysis}

The Hongsu chicken dish was ground into meat batter. The moisture content was measured gravimetrically in triplicate by drying $5 \pm 0.5$ g samples at $103 \pm 2{ }^{\circ} \mathrm{C}$ until constant weight (GBT 9695.15-2008, National Standard of China).

\subsection{2 | Weight loss}

After each heating treatment, the samples were cooled at room temperature for 30 min and wiped with blotting paper to calculate weight losses as follow (Chang et al., 2011).

$$
\text { Weight loss }=\left[\left(\mathrm{m}_{\mathrm{b}}-\mathrm{m}_{\mathrm{a}}\right) / \mathrm{m}_{\mathrm{b}}\right] \times 100 \%
$$

Where $\mathrm{m}_{\mathrm{a}}$ and $\mathrm{m}_{\mathrm{b}}$ are the weight $(\mathrm{g})$ of the sample before and after heating respectively.

\subsection{3 | Color parameters analysis}

The surface color of Hongsu chicken dish was measured by using a colorimeter (Chroma Meter CR-400, Konica Minolta Inc., Tokyo, Japan). The colorimeter was calibrated with a white standard board before testing. $L^{*}$ represents lightness (100 is total white, 0 is total black), a ${ }^{*}$ represents redness (positive value represents red, negative value represents green), and $b^{*}$ represents yellowness (positive value represents yellow, negative value represents blue). Three randomly selected points of the meat surface were measured individually, and the average results were calculated. The total color difference $(\Delta E)$ was calculated as:

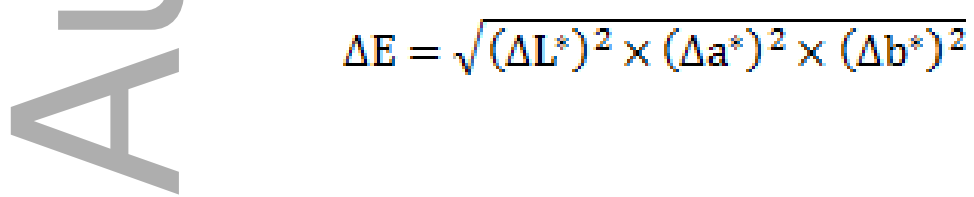

\subsection{4 $\mid$ Texture profile analysis (TPA)}

Texture properties of Hongsu Chicken dishes were measured as described by Bourne (1978) using Texture Profile Analysis (TPA) model of a texture analyzer This article is protected by copyright. All rights reserved 
155 (TA-XT2i, Stable Micro Systems Ltd., Surrey, England). The samples were balanced at room temperature for $3 \mathrm{~h}$, and then cut into cubes $(1 \times 1 \times 1 \mathrm{~cm})$ along the muscle fiber direction. The conditions of TPA were as follows: P/36R flat cylindrical probe, pre-test speed $2.0 \mathrm{~mm} / \mathrm{s}$, test speed $1.0 \mathrm{~mm} / \mathrm{s}$, post-test speed $2.0 \mathrm{~mm} / \mathrm{s}$, trigger force 5 $\mathrm{g}$, and two consecutive cycles at $30 \%$ compressions separated by a $5 \mathrm{~s}$ interval. The TPA parameters including hardness, springiness, cohesiveness, gumminess, and chewiness were computed. Six measurements were done for each sample and averages were reported.

\subsection{5 | Sensory analysis}

The Hongsu chicken dishes were evaluated by 10 trained and experienced sensory evaluation panelists (five males and five females) with the age of 23-27 (Liu, Zhang, Xu, Fang, \& Zheng, 2015). The appearance, odor, taste and texture of the chicken meat were evaluated using nine-point hedonic rating scales from 1 (dislike extremely) to 9 (like extremely), where $7-9=$ good, $4-6=$ moderate and 1-3 = poor. The criteria for sensory evaluation of Hongsu chicken are present in Table 1.

\subsection{6 | Flavor parameters analysis}

The flavor parameters of the heated and unheated Hongsu chicken samples were measured by using an electronic nose (Isenso Intelligent Technology Co. Ltd., Shanghai, China), each sample was fully chopped and mixed in advance. The electronic nose system consists of a gas sampling system, a chemical sensor array, a signal preprocessing circuit, a pattern-recognition software and odor expression. The sensor array had 14 different metal oxide gas sensors which respond to different flavor compounds (Table 2). About $5 \mathrm{~g}$ of samples was taken into a glass tube fitted 
with plastic cap and equilibrated at $25 \pm 2{ }^{\circ} \mathrm{C}$ for $60 \mathrm{~min}$. The detection time of each sample was $120 \mathrm{~s}$, and the sensors were cleaned for $120 \mathrm{~s}$ before another measurement.

\subsubsection{Taste parameters analysis}

An electronic tongue (TS-SA402B, Intelligent Sensor Technology Inc., Kanagawa, Japan) consisting of an automatic sampler, a selective sensor array of 8 sensors (sourness, bitterness astringency, umami, richness saltiness, richness, aftertaste-A, aftertaste-B), a signal acquisition instrument and a pattern recognition software was used to analyze the sample taste. The Hongsu chicken dish was mixed with distilled water (1:4) $\mathrm{g} / \mathrm{mL}$ and ground for $1 \mathrm{~min}$ by using a meat grinder. The mixture was moved into $50 \mathrm{ml}$ centrifuge tubes and centrifuged (Sigma 3-18 K, Sigma, German) at 4,000rpm for $5 \mathrm{~min}$. The supernatant was filtered through three layers of gauze and the clear liquid was poured into the special beaker of the electronic tongue, and then analyzed at room temperature. The taste signals were collected for $120 \mathrm{~s}$ for each sample, and the sensors were cleaned using distilled water before another measurement.

\subsection{8 | Data analysis}

Except of specifically stated, all experiments and measurements were repeated three times. The experimental data were averaged and expressed as mean \pm standard deviation. One-way analysis of variance (ANOVA) was performed using SPSS 20.0 software (IBM, Chicago, IL, USA), and mean values were identified as significantly different when $\mathrm{P}<0.05$.

\section{3 | RESULTS AND DISCUSSION}

\subsection{Moisture contents and reheating time}

To reach the center temperature of Hongsu chicken dish of $72{ }^{\circ} \mathrm{C}$, only $3.21 \mathrm{~min}$ was needed for microwave heating, while this for water boiling, steaming and 
roasting was $21.12 \mathrm{~min} 12.71 \mathrm{~min}$ and $12.27 \mathrm{~min}$ respectively (Table 3), indicating the reheating time by conventional methods was much longer than that of microwave heating.

211 Water plays an important role in food, and is closely related to meat tenderness 212 and juiciness (Van Oeckel, Warnants, \& Boucque, 1999). After reheating, the 213 moisture contents in all samples were decreased significantly, especially in the oven 214 roasting ones (Table 3), which could be attributed to its higher temperature and longer treatment time. The moisture content in the microwave heated sample was higher than the oven roasted sample, which was mainly because of the shorter time of microwave heating. However, the water boiling and steaming treated chicken dishes had relatively higher moisture contents than the oven roasting and microwave heating samples. This is understandable since these two methods were using water as heating media.

Weight loss is a negative attribute of prepared meat products from an aesthetic and economic perspective (Selby et al., 2006). The oven roasting sample had the highest $(\mathrm{P}<0.05)$ weight loss $(13.73 \%)$, followed by water boiling sample $(10.46 \%)$ (Table 3), while there were no significant differences between the steaming and microwave heating samples. Weight loss was caused by the loss of water and muscle fragments, the volatilization of fat and partial free fatty acids during the heating process (Liu et al., 2015). Barge et al. proposed that the loss of water was the main cause of weight loss (Barge, Destefanis, Toscano, \& Brugiapaglia, 1991).

\section{2 $\mid$ Color attributes}

A survey of consumer behavior reported that consumers generally believe that food color significantly correlate with its quality (Eagerman 1978). In the present study, both microwave heating and oven roasting significantly $(\mathrm{P}<0.05)$ decreased $\mathrm{L}^{*}$ value but increases $a^{*}$ and $b^{*}$ values (Table 4), showing that the oven and microwave heating resulted in a bright and golden color, therefore the samples might be more attractive in terms of the appearance. When comparing total color difference $(\Delta \mathrm{E})$, no significant differences were detected between the reheating methods of water boiling and steaming. However, $\Delta \mathrm{E}$ was significantly higher $(\mathrm{P}<0.05)$ for oven roasted sample than that of water boiling, steaming and microwave heating ones (Table 4).

241 which contributed to the bright and golden color. The $\Delta \mathrm{E}$ had no significant This article is protected by copyright. All rights reserved 
difference in samples reheated with water boiling, steaming and microwave methods (Table 4), suggesting the sample color differences might be minimal.

\subsection{Texture profile}

Texture is another important attribute to assess the quality and acceptability of a food product (Sikora, Juszczak, Sady, \& Krawontka, 2003). The shear force is negatively correlated with the meat tenderness (Boleman et al., 1997; Koohmaraie, Kent, Shackelford, Veiseth, \& Wheeler, 2002). Table 5 demonstrates that the hardness, chewiness and shear force of water boiling, steaming and microwave heating samples were decreased, suggesting these techniques improved the texture property and possibly eating quality. In addition, microwave heated samples had the highest springiness value than other samples. During the heating process, rupture of muscle fibers may cause damage to the integrity of space structures, and the collagen in the meat connective tissue was hydrolyzed into gelatin. These reactions will soften the meat samples and increase the tenderness (Yang \& Dong, 2009; Zu et al., 2016). However, there was no significant difference in hardness, tenderness and shear force between the oven roasting sample and the control sample, probably because the temperature in the oven was high and the water loss was severe from the product, resulting tougher texture.

\section{4 $\mid$ Sensory evaluation}

Sensory evaluation is an important method for evaluating the comprehensive quality of food (Kang et al., 2014). As can be seen from Table 6, the oven roasting sample had significantly $(\mathrm{p}<0.05)$ lower taste score than the other samples, while the other reheating methods did not significantly affect the taste of Hongsu chicken dishes. The roasting sample had a unique aroma of Hongsu chicken dish. The samples reheated with water boiling and steaming methods had a little unpleasant aroma. The aroma of microwave heated sample was better than that of water boiling and steaming samples, but was not as good as the oven heated one. Liu et al. (2017) also observed that the lamb aroma reheated with oven was better than that of microwave heating. In terms of color, the roasted sample had the highest color score with an attractive golden color, which may increase the consumers' appetite (Table 6). The color score of the microwave heated sample was lower, but it was higher than those of water boiling, steaming and control samples. The microwave heated samples had no 
significant difference with the control in the appearance score, while the other three samples had lower appearance values, especially the steaming sample (Table 6). The overall score of control (untreated samples), microwave, and oven roasting samples were not significantly different, but the microwave heated sample was significantly higher than the water boiling and steaming samples, indicating the microwave heated dish might be more acceptable by the panelists and potentially consumers.

\section{5 | Electronic nose analysis}

The principal component analysis (PCA) is mainly used for data conversion and dimension reduction of the eigenvector matrix of the sensor response values ( $\mathrm{Li}$, Deng, Wang, Cui, \& He, 2017). The linear classification of the eigenvector after reducing the dimension is carried out, and the classification results are presented in the form of scatter diagram. When the cumulative variance contribution rate is above $85 \%$, it can be considered that the selected principal components reflect the information of the original index (Moreno-Rojas, Sanchez-Segarra, Camara-Martos, \& Amaro-Lopez, 2010).

The PCA results of electronic nose analysis of Hongsu chicken dishes are presented in Fig. 1. The ellipse represents the overall characteristic of a single sample, and the distance of the graphic represents the odor difference between the samples. The principal components PC1 and PC2 accounted for $70.88 \%$ and $18.98 \%$ of the total variance respectively, and the cumulative contribution rate of PC1 and PC2 accounted for $89.86 \%$, indicating they could reflect most of the information of the original data. This also suggested that the samples with different reheating methods can be distinguished well from the control group in terms of their flavor. The data of water boiling sample and steaming sample were mixed up, which reflected that their flavors were similar. The flavor characteristics of oven and microwave treated samples were far away from those of the control, water boiling group and steaming group, and the distance between each other was also far, which indicated that the electronic nose could clearly distinguish the difference between oven, microwave heated sample and other samples.

\section{6 | Electronic tongue analysis}

The taste data obtained by electronic tongue analysis were also analyzed by principal component analysis (PCA), and the results are shown in Fig. 2. The smaller This article is protected by copyright. All rights reserved 
the distance between samples, the closer their quality characteristics (Cong, Yi, \& Zheng, 2015). The contribution rates of PC1, PC2 and PC3 were 55.02\%, 21.06\% and $17.43 \%$ respectively, and the cumulative contribution rate was up to $93.51 \%$, so the three principal components can reflect the major information of the whole samples. Fig. 2 also indicates that the distance between the microwave heating sample and the unheated sample was relatively close, indicating the taste difference between them was relatively small, which suggested that the microwave heating could maintain most of the original taste of the Hongsu chicken dish.

\section{4 | CONCLUSION}

To investigate the effects of different reheating methods on the quality of Hongsu chicken dishes, water boiling, steaming, microwave heating and oven roasting techniques were applied. Compared with other methods, microwave heating was quicker, resulted in meat sample with better color and taste, and lower weight loss. Therefore, this technique could be used in reheating of Hongsu chicken dishes and potentially for other prepared meats.

\section{ACKNOWLEDGEMENTS}

This work was financially supported by National Key R \& D Program of China (Contract No. 2017YFD0400501), National First-Class Discipline Program of Food Science and Technology (No. JUFSTR20180205) and Jiangsu Province Key

Laboratory Project of Advanced Food Manufacturing Equipment and Technology (No. FMZ201803),

\section{REFERENCES}

Barge, M. T., Destefanis, G., Toscano, G. P., \& Brugiapaglia, A. (1991). Two reading techniques of the filter paper press method for measuring meat water-holding capacity. Meat Science, 29(2), 183.

Boleman, S. J., Boleman, S. L., Miller, R. K., Taylor, J. F., Cross, H. R., Wheeler, T. L., Savell, J. W. (1997). Consumer evaluation of beef of known categories of tenderness. Journal Of Animal Science, 75(6), 1521-1524.

Bourne, M. (1978). Texture profile analysis. Journal of Food Science, 32, 62-67.

Chang, H. J., Wang, Q. A., Xu, X. L., Li, C. B., Huang, M., Zhou, G. H., \& Dai, Y. (2011). Effect of Heat-Induced Changes of Connective Tissue and Collagen on 
Meat Texture Properties of Beef Semitendinosus Muscle. International Journal Of Food Properties, 14(2), 381-396.

Cong, Y. J., Yi, H., \& Zheng, F. P. (2015). Taste distinguishing of yoghourts using electronic tongue. Science and Technology of Food Industry, 36(4), 49-52.

Ji, L., Xue, Y., Zhang, T., Li, Z. J., \& Xue, C. H. (2017). The effects of microwave processing on the structure and various quality parameters of Alaska pollock surimi protein-polysaccharide gels. Food Hydrocolloids, 63, 77-84.

Kang, Z. L., Zou, Y. F., Xu, X. L., Zhu, C. Z., Wang, P., \& Zhou, G. H. (2014). Effect of a beating process, as a means of reducing salt content in Chinese-style meatballs (kung-wan): A physico-chemical and textural study. Meat Science, 96(1), 147-152.

Kerry, J. F., Kerry, J. P., \& Kerry, J. F. (2011). Effects of novel thermal processing technologies on the sensory quality of meat and meat products, in Kerry, J. P., \& Kerry, J. F. ed, Processed Meats: Improving Safety, Nutrition and Quality, 617665. Woodhead Publishing Limited, Cambridge, UK. Kondjoyan, A., Kohler, A., Realini, C. E., Portanguen, S., Kowalski, R., Clerjon, S., . . . Debrauwer, L. (2014). Towards models for the prediction of beef meat quality during cooking. Meat Science, 97(3), 323-331.

Koohmaraie, M., Kent, M. P., Shackelford, S. D., Veiseth, E., \& Wheeler, T. L. (2002). Meat tenderness and muscle growth: is there any relationship? 3 Names are necessary to report factually on available data; however, the USDA neither guarantees nor warrants the standard of the product, and the use of the name by USDA implies no approval of the product to the exclusion of others that may also be suitable. Meat Science, 62(3), 345-352. doi: https://doi.org/10.1016/S0309-1740(02)00127-4

Li, S. Y., Deng, L., Wang, X., Cui, J., \& He, C. Y. (2017). Comparative Analysis of the Effect of Different Storage Methods on the Flavor of Small Fragrant Chicken Broth by Electronic Nose and Electronic Tongue. Meat Research, 31(4), 50-55.

Liu, D. Y., Tan, Y., Gai, S. M., Feng, N., Guan, D. X., \& Zhang, H. L. (2015). Changes in Fatty Acid Composition and Fat Content during Processing of Braised Pork Belly in Brown Sauce. Food Science, 36(23), 28-32. 
Liu, Q., Zhang, M., Xu, B. G., Fang, Z. X., \& Zheng, D. D. (2015). Effect of radio frequency heating on the sterilization and product quality of vacuum packaged Caixin. Food And Bioproducts Processing, 95, 47-54.

Liu, W. J., \& Lanier, T. C. (2016). Rapid (microwave) heating rate effects on texture, fat/water holding, and microstructure of cooked comminuted meat batters. Food Research International, 81, 108-113.

Liu, Y. N., Su, L. Y., Wei, X. X., Li, X. N., \& Yang, H. Y. (2017). Effect of eating quality and the volatile flavor in roast whole lamb by different reheating ways. Food Science And Technology, 42(6), 124-127.

Lorenzo, J. M., Cittadini, A., Munekata, P. E., \& Dominguez, R. (2015). Physicochemical properties of foal meat as affected by cooking methods. Meat Science, 108, 50-54.

Ministry of Health. (2005). Good operating practices for food catering industry. (5), 449-464.

Moreno-Rojas, R., Sanchez-Segarra, P., Camara-Martos, F., \& Amaro-Lopez, M. A. (2010). Multivariate analysis techniques as tools for categorization of Southern Spanish cheeses: nutritional composition and mineral content. European Food Research And Technology, 231(6), 841-851.

Pu, G. Y., Song, G. L., Song, C. F., \& Wang, J. (2017). Analysis of thermal effect using Coupled Hot-air and Microwave heating at different position of potato. Innovative Food Science \& Emerging Technologies, 41, 244-250.

Salazar-Gonzalez, C., San Martin-Gonzalez, M. F., Lopez-Malo, A., \& Sosa-Morales, M. E. (2012). Recent Studies Related to Microwave Processing of Fluid Foods. Food And Bioprocess Technology, 5(1), 31-46.

Schellekens, M. (1996). New research issues in sous-vide cooking. Trends In Food Science \& Technology, 7(8), 256-262.

Selby, T. L., Berzins, A., Gerrard, D. E., Corvalan, C. M., Grant, A. L., \& Linton, R. H. (2006). Microbial heat resistance of Listeria monocytogenes and the impact on ready-to-eat meat quality after post-package pasteurization. Meat Science, 74(3), 425-434.

Sikora, M., Juszczak, L., Sady, M., \& Krawontka, J. (2003). Use of starch/xanthan gum combinations as thickeners of cocoa syrups. Nahrung-Food, 47(2), 106-113. Sun, D. W. (2005). Emerging Technologies for Food Processing. Academic Press. 
Vadivambal, R., \& Jayas, D. S. (2010). Non-uniform Temperature Distribution During Microwave Heating of Food Materials-A Review. Food And Bioprocess Technology, 3(2), 161-171.

Van Oeckel, M. J., Warnants, N., \& Boucque, C. V. (1999). Comparison of different methods for measuring water holding capacity and juiciness of pork versus online screening methods. Meat Science, 51(4), 313-320.

Wills, T. M., DeWitt, C. A. M., Sigfusson, H., \& Bellmer, D. (2006). Effect of cooking method and ethanolic tocopherol on oxidative stability and quality of beef patties during (oxidative stability of refrigerated storage cooked patties). Journal Of Food Science, 71(3), C109-C114.

Yang, J. L., \& Dong, Q. (2009). Effect of Microwave Sterilization on Texture Characteristics of Pork with Sweet Soybean Paste. Food Science, 30(23), 27-31.

Zhang, M., Tang, J., Mujumdar, A. S., \& Wang, S. (2006). Trends in microwaverelated drying of fruits and vegetables. Trends In Food Science \& Technology, 17(10), 524-534.

Zu, X., Liao, T., Geng, S., Li, X., Ye, L., \& Xiong, G. (2016). Effect of Microwave Sterilization Time and Power on the Meat Quality of Micropterus salmoides. The Food Industry(12), 77-80.

\section{Figure captions}

Fig. 1 Principal component analysis plot of electronic nose sensor response signals for Hongsu chicken dishes using different reheating methods ( $\lambda$ : control; $\triangleright$ : water boiling; $\diamond$ : steaming; $\Delta$ : microwave heating; +: oven roasting)

Fig. 2 Principal component analysis plot of electronic tongue sensor response signals for Hongsu chicken dishes using different reheating methods $(\mathrm{x}$ : control; $\Delta$ : water boiling; $\square$ : steaming; ०: microwave heating; $\square$ : oven roasting).

\begin{tabular}{|c|c|c|}
\hline Characteristics & Standard & Scores \\
\hline \multirow{3}{*}{ Appearance } & Complete shape, better to keep the original form of the meat & $7-9$ \\
\hline & A slight change in shape & $4-6$ \\
\hline & The shape dispersed, and damaged seriously. & $1-3$ \\
\hline \multirow{2}{*}{ Taste } & Good viscoelasticity and juiciness, proper hardness, not greasy & $7-9$ \\
\hline & Low or high hardness, a little dryness and greasy & $4-6$ \\
\hline
\end{tabular}


Bad viscoelasticity and juiciness, very low or high hardness, greasy

A strong smell of Hongsu chicken with no peculiar smell 7-9

Flavor

Lack of a strong aroma or slight peculiar smell

4-6 no meat aroma, peculiar smell $1-3$

\begin{tabular}{llc} 
& Attractive color and lustre & $7-9$ \\
\cline { 2 - 3 } Color & Normal color and lustre & $4-6$ \\
& Poor color and lustre & $1-3$ \\
\hline
\end{tabular}

434

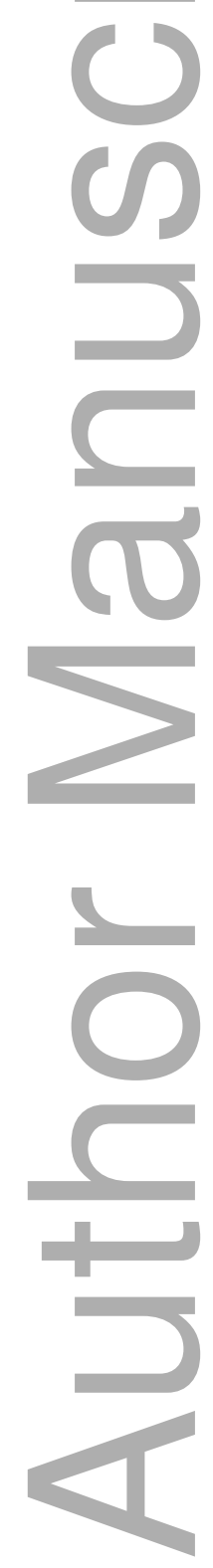


Table 2 Sensors used and their main applications in the electronic nose

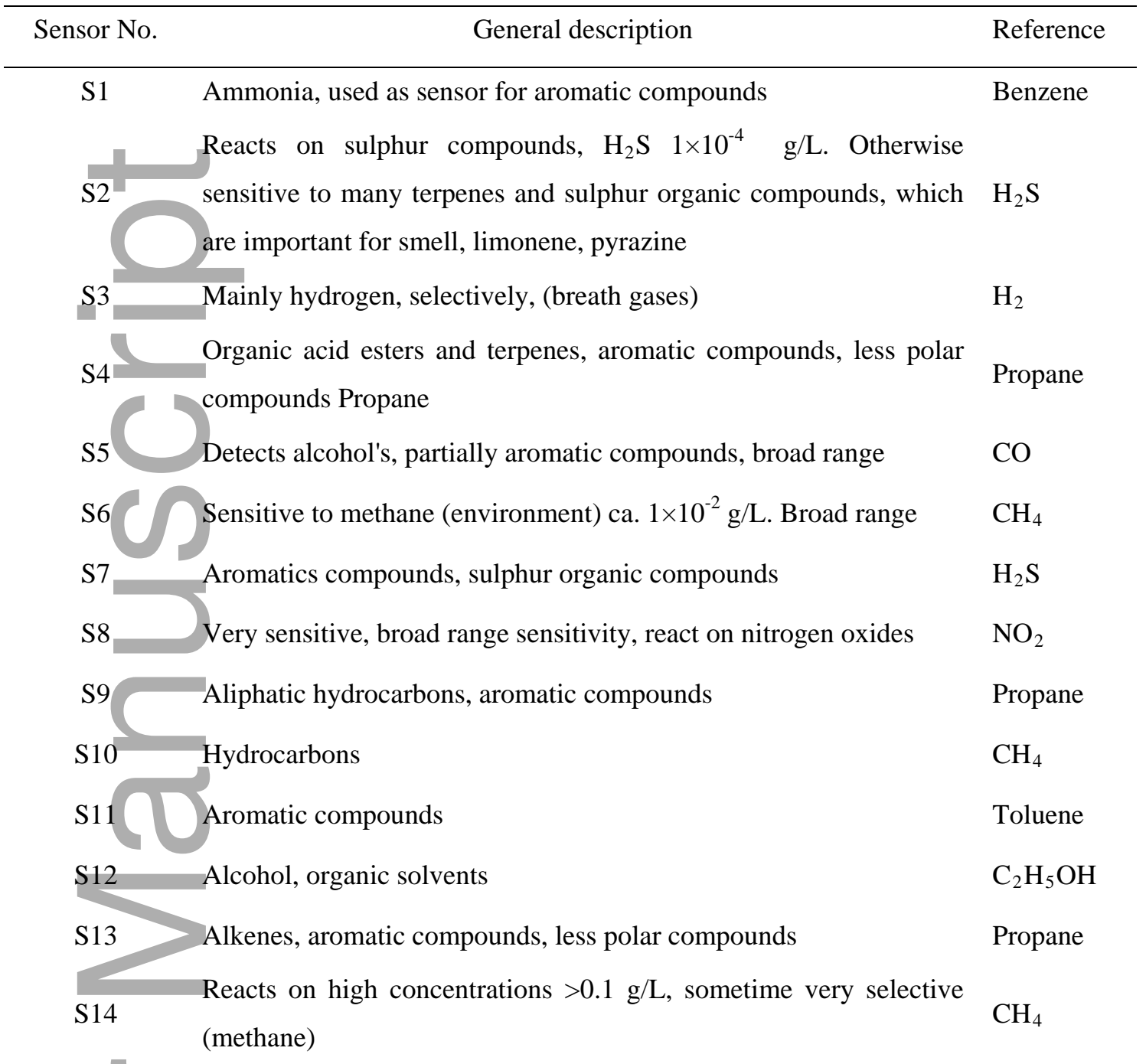

Table 3 Heating time (to reach center temperature of $72{ }^{\circ} \mathrm{C}$ ), weight loss and moisture content of

Hongsu chicken dishes using different reheating methods

\begin{tabular}{cccc}
\hline $\begin{array}{c}\text { Reheating } \\
\text { Methods }\end{array}$ & Time (min) & $\begin{array}{c}\text { Weight loss } \\
(\%)\end{array}$ & Moisture content (\%) \\
\hline Control & $\mathrm{N}$ & $\mathrm{N}$ & $68.83 \pm 0.18^{\mathrm{a}}$ \\
Water boiling & $21.12 \pm 1.07^{\mathrm{a}}$ & $10.46 \pm 0.28^{\mathrm{b}}$ & $66.63 \pm 0.35^{\mathrm{b}}$ \\
Steaming & $12.72 \pm 1.02^{\mathrm{b}}$ & $9.24 \pm 0.44^{\mathrm{c}}$ & $67.09 \pm 0.47^{\mathrm{b}}$ \\
Microwave heating & $3.21 \pm 0.32^{\mathrm{c}}$ & $9.47 \pm 0.22^{\mathrm{c}}$ & $64.21 \pm 0.43^{\mathrm{c}}$ \\
Oven roasting & $12.27 \pm 0.90^{\mathrm{b}}$ & $13.73 \pm 0.39^{\mathrm{a}}$ & $58.48 \pm 0.21^{\mathrm{d}}$ \\
\hline
\end{tabular}

438 Data are mean \pm standard deviation.

439 Values with different superscripts in the same column represent significant differences $(P<0.05)$. 
Table 4 Color parameters of Hongsu chicken dishes using different reheating methods

\begin{tabular}{ccccc}
\hline $\begin{array}{c}\text { Reheating } \\
\text { methods }\end{array}$ & $\mathrm{L}^{*}$ & $\mathrm{a}^{*}$ & $\mathrm{~b}^{*}$ & $\Delta \mathrm{E}$ \\
\hline Control & $68.14 \pm 0.15^{\mathrm{a}}$ & $2.37 \pm 0.35^{\mathrm{c}}$ & $16.02 \pm 0.45^{\mathrm{c}}$ & \\
Water boiling & $65.01 \pm 0.68^{\mathrm{b}}$ & $3.36 \pm 0.52^{\mathrm{bc}}$ & $17.14 \pm 0.39^{\mathrm{c}}$ & $3.96 \pm 0.51^{\mathrm{b}}$ \\
Steaming & $68.60 \pm 0.93^{\mathrm{a}}$ & $2.41 \pm 0.46^{\mathrm{c}}$ & $17.18 \pm 1.01^{\mathrm{c}}$ & $3.85 \pm 0.76^{\mathrm{b}}$ \\
Microwave heating & $64.56 \pm 0.35^{\mathrm{b}}$ & $3.47 \pm 0.11^{\mathrm{b}}$ & $20.65 \pm 0.64^{\mathrm{b}}$ & $3.99 \pm 0.70^{\mathrm{b}}$ \\
Oven roasting & $60.24 \pm 0.22^{\mathrm{c}}$ & $3.89 \pm 0.87^{\mathrm{a}}$ & $26.99 \pm 0.64^{\mathrm{a}}$ & $14.52 \pm 0.45^{\mathrm{a}}$ \\
\hline
\end{tabular}

442 Data are mean \pm standard deviation.

443 Values with different superscripts in the same column represent significant differences $(P<0.05)$.

444 Table 5 The texture profile of Hongsu chicken dishes using different reheating methods

\begin{tabular}{|c|c|c|c|c|}
\hline $\begin{array}{c}\text { Reheating } \\
\text { methods }\end{array}$ & Springiness & Cohesiveness & Chewiness & $\begin{array}{l}\text { Shear force } \\
\text { (N) }\end{array}$ \\
\hline $835.05 \pm 77.09^{a}$ & $0.73 \pm 0.032$ & $0.56 \pm 0.015$ & $349.36 \pm 26.93^{\mathrm{a}}$ & $16.43 \pm 1.1^{\mathrm{a}}$ \\
\hline Water boiling $\quad 420.82 \pm 50.82^{c}$ & $0.82 \pm 0.016^{b}$ & $0.68 \pm 0.034^{\mathrm{a}}$ & $232.84 \pm 17.18^{\mathrm{c}}$ & $12.34 \pm 0.71^{\mathrm{bc}}$ \\
\hline Steaming $\quad 455.61 \pm 45.67^{c}$ & $0.83 \pm 0.015^{\mathrm{b}}$ & $0.68 \pm 0.014^{\mathrm{a}}$ & $256.71 \pm 26.79^{c}$ & $11.43 \pm 1.52^{\mathrm{c}}$ \\
\hline Microwave $\quad 599.22 \pm 36.31$ & $0.87 \pm 0.011^{\mathrm{a}}$ & $0.63 \pm 0.019^{\mathrm{b}}$ & $307.96 \pm 24.85^{b}$ & $14.02 \pm 0.93^{b}$ \\
\hline 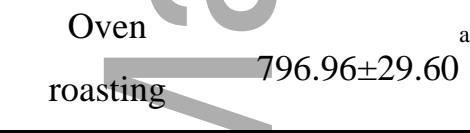 & $0.75 \pm 0.018^{\mathrm{c}}$ & $0.59 \pm 0.021^{\mathrm{c}}$ & $352.28 \pm 16.67^{\mathrm{a}}$ & $15.93 \pm 0.45^{\mathrm{a}}$ \\
\hline
\end{tabular}

445 Data are mean \pm standard deviation.

446 Values with different superscripts in the same column represent significant differences $(P<0.05)$.

447 Table 6 Sensory evaluation of Hongsu chicken dishes using different reheating methods

\begin{tabular}{cccccc}
\hline $\begin{array}{c}\text { Reheating } \\
\text { methods }\end{array}$ & Taste & Flavor & Color & Appearance & Overall \\
\hline Control & $6.01 \pm 0.87^{\mathrm{ab}}$ & $5.89 \pm 1.01^{\mathrm{bc}}$ & $6.09 \pm 0.37^{\mathrm{c}}$ & $8.8 \pm 0.82^{\mathrm{a}}$ & $6.57 \pm 0.66^{\mathrm{ab}}$ \\
Water boiling & $6.84 \pm 0.93^{\mathrm{a}}$ & $5.04 \pm 0.67^{\mathrm{c}}$ & $5.99 \pm 0.58^{\mathrm{c}}$ & $7.29 \pm 0.67^{\mathrm{b}}$ & $6.23 \pm 0.73^{\mathrm{b}}$ \\
Steaming & $6.78 \pm 0.85^{\mathrm{a}}$ & $5.82 \pm 0.58^{\mathrm{bc}}$ & $5.67 \pm 0.79^{\mathrm{c}}$ & $4.33 \pm 0.76^{\mathrm{d}}$ & $5.78 \pm 0.74^{\mathrm{b}}$ \\
Microwave & $7.49 \pm 0.65^{\mathrm{a}}$ & $7.15 \pm 0.61^{\mathrm{b}}$ & $7.11 \pm 0.37^{\mathrm{b}}$ & $8.49 \pm 0.41^{\mathrm{ab}}$ & $7.51 \pm 0.32^{\mathrm{a}}$ \\
Oven roasting & $5.01 \pm 0.44^{\mathrm{b}}$ & $8.46 \pm 0.63^{\mathrm{a}}$ & $8.14 \pm 0.51^{\mathrm{a}}$ & $5.84 \pm 0.58^{\mathrm{c}}$ & $6.84 \pm 0.51^{\mathrm{ab}}$ \\
\hline
\end{tabular}

448 Data are mean \pm standard deviation.

449 Values with different superscripts in the same column represent significant differences $(P<0.05)$. 


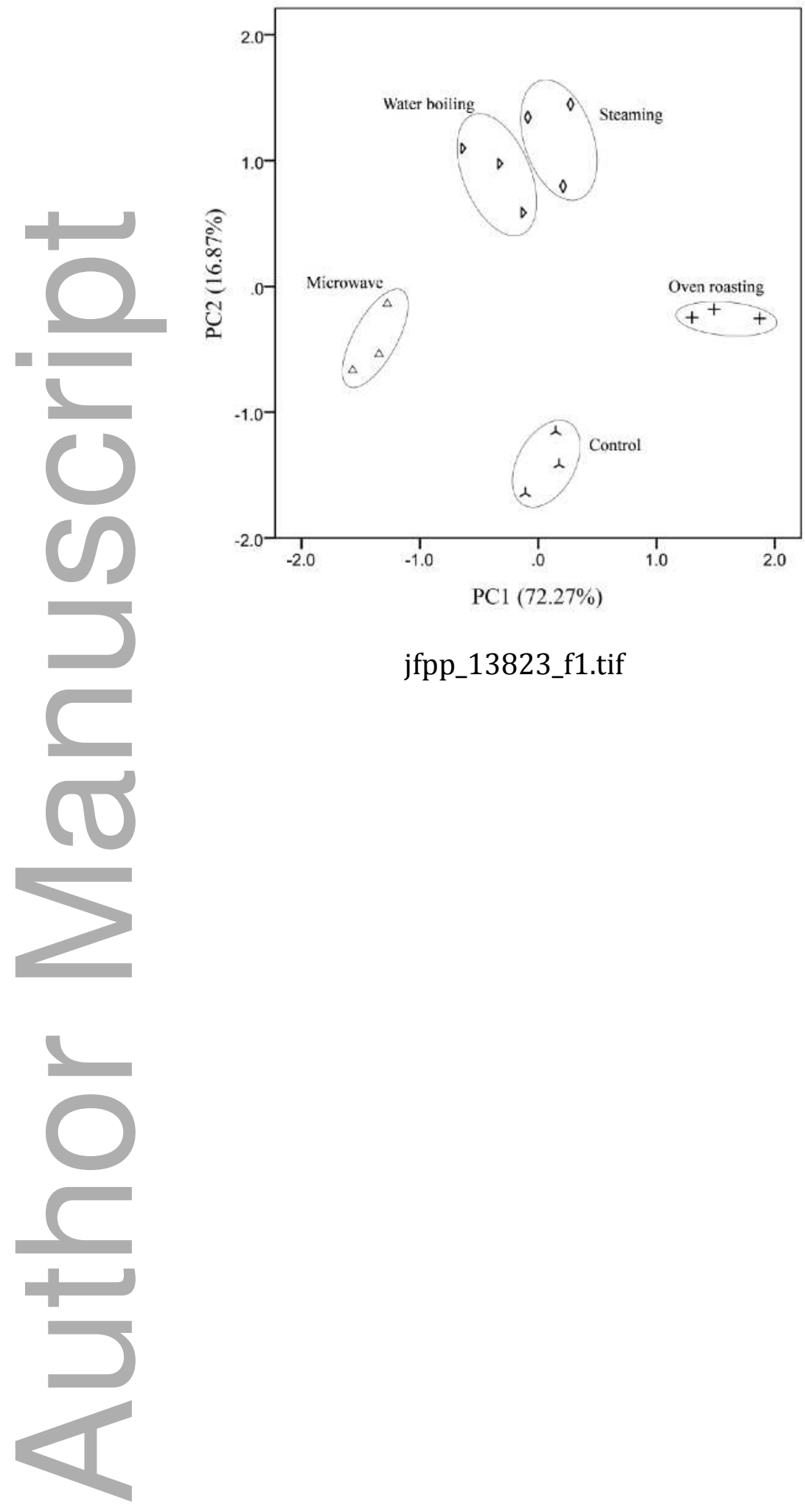

This article is protected by copyright. All rights reserved 


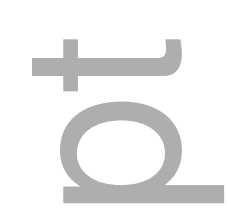

$\square$
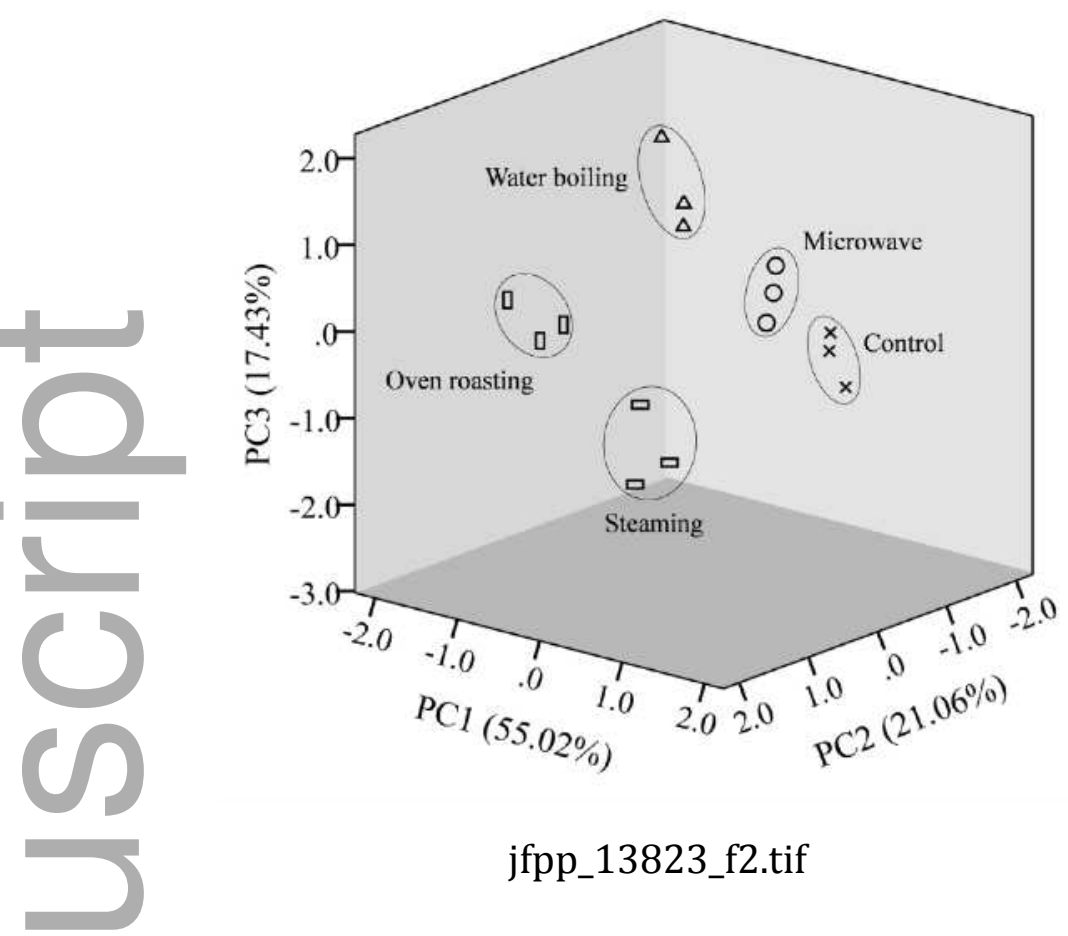

jfpp_13823_f2.tif
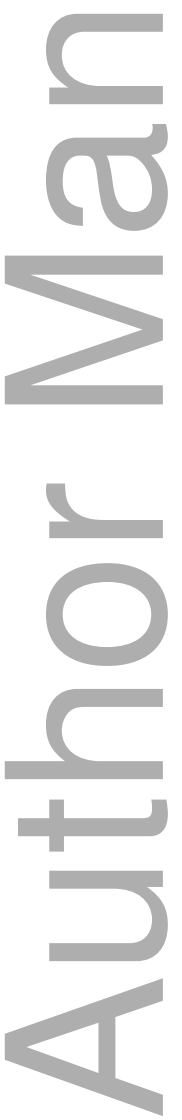


\section{University Library}

\section{- M M N E R VA A gateway to Melbourne's research publications}

Minerva Access is the Institutional Repository of The University of Melbourne

Author/s:

Wang, J;Zhang, M;Fan, K;Yang, C-H;Fang, Z

Title:

Effects of reheating methods on the product quality of Hongsu chicken dish

Date:

2018-11-01

Citation:

Wang, J., Zhang, M., Fan, K., Yang, C. -H. \& Fang, Z. (2018). Effects of reheating methods on the product quality of Hongsu chicken dish. JOURNAL OF FOOD PROCESSING AND PRESERVATION, 42 (11), https://doi.org/10.1111/jfpp.13823.

Persistent Link:

http://hdl.handle.net/11343/284805 